

\title{
Fotografar prejudica a memória?
}

\author{
Does photography damage the memory?
}

\author{
Nina Velasco e Cruz* \\ Manuela Salazar**
}

\begin{abstract}
Resumo: Este artigo discute as múltiplas relações entre o ato de fotografar e a memória, na era digital. Partindo de um artigo a respeito do impacto da fotografia sobre a memória, da americana Linda Henkel, levantamos alguns questionamentos a respeito da relação da fotografia com nossas lembranças. Existe algo no ato fotográfico que prejudique a construção de memórias? Fotografamos para lembrar? O que escolhemos fotografar importa? O acúmulo de fotografias ajuda ou atrapalha a construção da memória?
\end{abstract}

Palavras-chave: Fotografia. Memória. Esquecimento. Mediação.

Abstract: This paper is about the multiple relations between
the photographic act and memory, in the digital age. Starting
from a paper about the impact that photography has on the
memory, by Linda Henkel, we raise certain questions about the
relation between photographs and our remembering process.
Is there anything in the photographic act that damages the
construction of memories? Do we photograph to remember?
What we choose to photograph matters? Does the accumulation
of photographs helps or disturbs the construction of memory?

Keywords: Photography. Memory. Forgetting. Mediation.

\footnotetext{
* Professora Adjunta do Departamento de Comunicação Social na Universidade Federal de Pernambuco, onde ministra disciplinas no curso de Cinema e no Programa de Pós-Graduação em Comunicação. É doutora em Tecnologias da Comunicação e Estética pela Universidade Federal do Rio de Janeiro.

** Mestranda do Programa de Pós-Graduação em Comunicação (UFPE).
} 


\section{Introdução}

Muito se fala hoje sobre o acúmulo de imagens na fotografia vernacular. Uma pesquisa realizada pela Shutterfly, Inc (STIER, 2013) revelou que das 10 bilhões de imagens produzidas por mês nos Estados Unidos, metade nunca chega ser compartilhada. A pesquisa aponta para uma dita situação de "risco" das memórias, principalmente entre os adolescentes, que, segundo os dados, não têm mais o hábito de revisitar fotografias antigas. O quadro traçado é temerário: há um excesso de imagens fotográficas, que, relegadas ao esquecimento precoce, arruínariam a memória. Ansiosos, estaríamos fotografando vorazmente para que nossas memórias não se dissipem no tempo (BATCHEN, 2004), mas o ato fotográfico acaba por figurar entre os grandes responsáveis pela volatilidade das lembranças no mundo contemporâneo. As mudanças do filme para o digital, do álbum para o perfil do Instagram, do físico para o virtual, são frequentemente apontadas como raízes desta ambiguidade, que coloca a fotografia no centro das dúvidas sobre o presente e o futuro da memória da humanidade.

$\mathrm{Na}$ ocasião da publicação do artigo Point-and-Shoot Memories: The Influence of Taking Photos on Memory for a Museum Tour, da especialista em psicologia cognitiva da Universidade de Fairfield, Linda Henkel (2013), sites publicaram artigos com títulos como: "Sem fotos, por favor: fotografar pode impedir a memória de um passeio no museu" (ASSOCIATION FOR PSYCHOLOGICAL SCIENCE, 2013) ou "Fotografar arruína sua memória?" (CHALABI, 2013). Nessas manchetes, se percebe como o resultado da pesquisa foi desdobrado: a fotografia surge como um instrumento no processo de degradação da memória, como se contribuísse para a "ruína" de uma percepção do passado tida como "adequada".

Questiona-se aqui uma abordagem apenas estatística na discussão sobre a relação entre o ato fotográfico e a memória. Não nos parece plausível este isolamento da fotografia, este olhar 
teleobjetivo sobre o quadro. O processo de construção de nossas memórias engloba "complexos fenômenos técnicos-cognitivosculturais" (DIJCK, 2007), repletos de particularidades, que acarretam outros desenvolvimentos e perguntas aos quais números podem não trazer respostas plausíveis. À discussão, visamos somar questionamentos e teorias provindo de outros âmbitos acadêmicos, conforme modelo interdisciplinar sugerido por Dijck (2007), cuja principal intenção é criar conexões entre as disciplinas que de outro modo permaneceriam ocultas, e inspirar inovação nas conceitualizações sobre memória pessoal.

[...] A academia não pode ignorar os paradigmas de pesquisa dos outros ao desenvolver novos horizontes sobre a memória na era digital. [...] Dificilmente podemos confiar em modelos e metáforas antigos para avançar nosso pensamento. A formação mútua da mente, da tecnologia e da cultura é uma premissa importante para o modelo proposto; seu objetivo modesto é juntar descobertas relevantes dessas várias perspectivas para ver como elas podem ajudar a redefinir problemas imanentes e multifacetados da pesquisa sobre memória [...] (DIJCK, 2007, p. 174, tradução dos autores) ${ }^{1}$.

É preciso, então, ampliar o enquadramento ao se questionar se o mero ato fotográfico, a experiência vivida pelo Operator, segundo terminologia de Barthes (1984), pode prejudicar o desenvolvimento das memórias. Fotografamos para lembrar? Estaríamos relegando nossas memórias a arquivos externos? O que escolhemos fotografar importa para nossas lembrança?

1 No original: [...] Academics cannot afford to ignore each other's research paradigms in developing new horizons on memory in the digital age. [...] We can hardly rely on old models and metaphors to advance our thinking. The mutual shaping of mind, technology, and culture is an important premise of the propose model; its modest goal is to pull together relevant finding from these various perspectives to see how they can help redefine immanent multifaceted problems in memory research [...]. 


\section{Memórias point and shoot}

Para Henkel (2014), as fotografias deixaram de ser lembranças preciosas para se tornarem mercadorias. Concedendo à nostalgia, a autora rememora décadas passadas, quando o custo mais elevado da fotografia nos permitia apenas capturar momentos "dignos" de serem guardados e de serem passados para outras gerações. Para ela, esses importantes momentos agora "definham" em meio às imagens nas plataformas digitais, junto ao "jantar de ontem à noite" e as "selfies", e nunca são revisitados. "Quando confiamos em auxílios para memória como câmeras e smartphones, nós efetivamente terceirizamos nossa habilidade de lembrar tirando do processamento cognitivo que é necessário para criar memórias duradouras" (HENKEL, 2014, tradução dos autores) ${ }^{2}$.

Partindo desta premissa, Henkel(2013) promove dois estudos para tentar mensurar o quanto a captura de imagens fotográficas de objetos impacta a memória subsequente dos indivíduos. São duas as hipóteses: fotografar objetos pode ser positivo à memória, pois a atenção mais focada eleva a "memorabilidade" de uma cena; ou fotografar pode ser negativo à memória, pois divide a atenção sobre um fato, e faz com que as pessoas confiem no aparelho para memorizar algo por elas.

Para testá-las, os participantes da pesquisa foram levados à visitas guiadas a um museu de arte, onde deveriam observar objetos pré-determinados e os fotografar ou não, conforme instrução prévia. Foram realizados dois experimentos: no primeiro, foi comparada a memória dos objetos fotografados com a de objetos apenas observados. No segundo, comparou-se a memória de objetos fotografados como um todo, objetos fotografados com zoom em um detalhe pré-determinado e objetos não fotografados. Eram duas etapas: a primeira, uma visita a um museu com pinturas

2 No original: When we rely on memory aids like cameras and smartphones we effectively outsource our ability to recall—taking away from the cognitive processing that's required to create lasting memories. 
e esculturas, e a segunda, no dia seguinte, num teste de perguntas em que deveriam escrever os nomes dos objetos de que lembravam, ou descrevê-los brevemente.

Em linhas gerais, o resultado demonstrou, para Henkel, um "efeito de prejuízo do ato de fotografar" ("photo-taking impairment effect") em relação à memória: fotografar prejudicou a capacidade de relembrar os nomes e os formatos dos objetos fotografados. Do primeiro experimento, conclui-se que a capacidade de enumerar posteriormente detalhes físicos de objetos foi afetada negativamente pelo ato de fotografá-los. Para assegurar que o efeito de prejuízo do ato de fotografar não tivesse como causa a falta de tempo, no segundo experimento, além de fotografar detalhes em zoom, os participantes ganharam um tempo adicional dedicado somente ao ato fotográfico. Mesmo assim, o resultado mostrou que os objetos fotografados foram menos rememorados que os não fotografados. Contudo, a maneira como eles foram fotografados mediou este efeito. "Quando eram fotografados com zoom em uma parte, a memória dos detalhes não era prejudicada e, de fato, era comparável à memória dos detalhes de quando os objetos foram apenas observados" (HENKEL, 2013, p. 5, tradução dos autores) 3 $^{3}$. Para a autora, fotografar detalhes protegeu a memória não somente para a parte destacada, mas para a totalidade da imagem. "O que a pessoa lembrava não era necessariamente o que a foto capturou: o 'olho da câmera' não é o 'olho da mente"' (HENKEL, 2013, p. 5, tradução nossa $)^{4}$.

$\mathrm{Na}$ conclusão do artigo, observa-se que pesquisas futuras deveriam investigar se efeitos similares ocorrem quando as pessoas estão livres para escolher quais objetos desejam fotografar, pois a tendência é que se fotografe mais aquilo que se valoriza ou se quer lembrar posteriormente. Também são enfatizados os atos de 3 No original: When objects were photographed by zooming in on one part, memory for details was not harmed and was, in fact, comparable to memory for details when objects were observed.

$4 \quad$ No original: Thus, what the person remembered was not necessarily what the camera shot captured - the camera's 'eye' is not the 'mind's eye'. 
revisitação e interação com as fotografias como possíveis métodos de preservação dessas memórias.

\section{Memórias e afetos}

Há um deslocamento entre essas conclusões e o experimento proposto. Ao colocar a ênfase no momento de interação posterior ao ato fotográfico e na possibilidade de escolha dos objetos fotografados para uma preservação da memória, Henkel (2013) acaba por apontar justamente o problema em seu objeto de pesquisa: a experiência promovida difere profundamente da fotografia realizada na "vida real". Ao visitar um museu, por exemplo, um indivíduo registra objetos que lhe chamam mais atenção, motivado por diversas causas. Sejam positivas, como afeto, desejo; neutras, como uma anotação visual; ou negativas, como tristeza, raiva etc. São fotografados aqueles objetos de que se deseja lembrar posteriormente, e a lembrança é acentuada pela prática eventual de revisitar os arquivos fotográficos.

Mesmo que não se recorde do nome, ou do formato do objeto, o Operator poderá se recordar do motivo específico que provocou $\mathrm{o}$ ato fotográfico pela própria imagem resultante. Para Kracauer (2009), em ensaio de 1927, quando comparada à fotografia, a memória é cheia de lacunas. Um retrato, por exemplo, traz pouco das histórias de vida de seus personagens, mas em sua iconicidade estão visíveis todas as rugas de uma face, assim como foram selecionadas por um desejo arbitrário do fotógrafo, por uma infinita série de filtros e razões. Enquanto a fotografia apreende o contínuo espacial e temporal, a memória pula dias, anos, dilata e encolhe distâncias, e conserva este contínuo apenas se ele significa alguma coisa.

Contrariando esta perspectiva, a pesquisa de Henkel (2013) traz uma noção de memória calcada apenas na memorização: os participantes são convidados a nomear, descrever a forma de 
determinado objeto ou até apontar o lugar onde ele foi avistado, mas, como se tratam de objetos pré-determinados, não se consideram aspectos importantes da construção da memória, como escolha, afeto e compartilhamento. Isso é ainda mais acentuado dado o tipo de experimento proposto pela pesquisadora, que envolve uma visita a um museu, onde, num contexto fotográfico da vida real, vivenciam-se experiências estéticas, que formam memórias fluídas, subjetivas, e ligadas ao espectro das sensações.

Seguindo a linha de pensamento de Kracauer, enquanto a fotografia é linear, a memória tem fronteiras difusas, é intensamente subjetiva, muitas vezes incoerente, e sempre mutável, praticamente uma "forma maleável de ficção" (BATCHEN, 2004). Esta é uma noção comum nos estudos de memória, inclusive em Freud, que entendia a memória como uma modalidade de operação entre a história e a fantasia, mediada através de representações (LANDSBERG, 2004). "Freud percebe a dificuldade em localizar algo como uma memória 'autêntica ou genuína"” (LANDSBERG, 2004, p. 15).

Landsberg (2004) nos traz um conceito de Marcel Proust, apresentado por Walter Benjamin: a distinção entre memória involuntária, o conjunto das lembranças sem mediações, e memória voluntária, o arquivo consciente, voluntarioso e artificial, a serviço do intelecto. Benjamin, em Sobre Alguns Temas de Baudelaire, privilegiava a memória involuntária em detrimento da voluntária, por ser esta mais "autêntica", enquanto a memória voluntária reduziria o escopo da imaginação. Apesar de Benjamin não fazer alusão direta à fotografia nesse ensaio, Landsberg acredita que a crítica feita à memória voluntária poderia ser estendida a esse tipo de reprodutibilidade técnica (ele alude diretamente ao texto jornalístico, por exemplo). Contudo, posteriormente, no inacabado Projeto das Passagens (Passagen-Werk), Benjamin reconheceria que esta distinção não se aplica à cultura das massas, e tenta superála. "Com essas novas tecnologias, fica possível haver uma memória mediada que alguém, não obstante, viva como real ou genuína" 
(LANDSBERG, 2004, p. 17) ${ }^{5}$. Benjamin nos traz a ideia de uma memória alojada não no corpo individual, mas em "configurações de objetos materiais" (LANSBERG, 2004, p. 164).

\section{A fotografia prejudica a memória?}

Este conceito de mediação é essencial para discutirmos a relação da memória e do ato fotográfico. Falar da fotografia como prejuízo ou ruína da memória é ignorar os contextos social, cultural e individual do próprio Operator. O empirismo presente no ato de isolar determinados atos fotográficos em um contexto ideal "de temperatura e pressão" não pode servir para estabelecer verdades sobre a memória e fotografia, por este se tratar de um meio onde se inserem inúmeros outros elementos de caracteres transitórios, não concretos e não mensuráveis, além da câmera, do sujeito e do clique. O processo que faz de um momento em um memento ${ }^{6}$ é muito mais complexo do que o contemplado por Linda Henkel em seu artigo.

Toda memória é mediada por um self, com a ajuda de instrumentos artificiais. Memórias verdadeiras são naturalmente transformadas; até mesmo as mais vívidas, detalhadas, e documentadas são necessariamente uma seleção de modalidades, e assim, nunca, compreensivas. Para esse conceito de memória, termos como 'verdadeiro' e 'falso' não valem mais (se é que um dia eles valeram), porque a memória é um fenômeno intrinsecamente mediado - mediado pelos caprichos da mente, da tecnologia e da cultura (DIJCK, 2007, p. 178, tradução dos autores). ${ }^{7}$

$5 \quad$ No original: With these new technologies it becomes possible to have a mediated memory that one nevertheless experiences as real or genuine.

6 Memento, no dicionário Oxford (2002, p. 500), é traduzido como lembrança.

7 No original: Every memory is mediated by a self, with the help of 
Ao colocar a fotografia como um espaço de memória externo em relação às lembranças mentais, Henkel (2013) trabalha com o binarismo que distingue a memória como uma capacidade interna da fisiologia humana e os objetos midiáticos como instrumentos externos que "terceirizam" esta capacidade, numa relação entre o que é corpóreo e o que é artificial e tecnológico. Desde a época de Platão, que considerou a invenção da escrita como prejudicial à memória, esses meios de "terceirização" de nossas capacidades físicas parecem gerar ressentimentos e discursos de ruína e fim da memória. Para Dijck (2007), as mídias, como a fotografia, e a memória não são entidades separadas que se corrompem, e sim formam um par numa relação de mediação.

Batchen (2004) investigou fotografias híbridas, objetos de fotografia vernacular cuja materialidade é sua principal qualidade: fotos enquadradas, com fios de cabelo, pingentes com fotografias etc. Elas seriam prova da memória como uma via de mão dupla: o ato de lembrança estabelece o lugar do indivíduo no tempo e no espaço, mas também em uma rede de relações sociais e históricas. É uma questão de projeção, um contínuo processo de devir. "Essas fotografias nos pedem que entreguemos algo de nós mesmos, para funcionarem de maneira satisfatória" (BATCHEN, 2004, p. 98, tradução dos autores). De maneira menos material, a fotografia vernacular digital se comporta de acordo com uma metáfora semelhante, como um objeto de memórias mediadas (DIJCK, 2007).

Tratam-se de itens produzidos em tecnologias da mídia, que mediam não só lembranças do passado, mas suas relações com indivíduos e os grupos aos quais fazem parte. Nós os utilizamos para "criar e recriar um sentido de passado, presente, e futuro em nós

articifical instruments. Truthful memories are naturally morphed; even the most vivid, detailed, and documented memory is necessarily a selection of modalities and thus never comprehensive. To such concept of memory, terms such as "true" and "false" no luonger apply (if they ever did), because memory is intrinsically a mediate phenomenon - mediated by the vagaries of mind, technology and culture. 
mesmos, em relação aos outros" (DIJCK, 2007, p. 21, tradução dos autores). A memória se trata aqui de uma atividade intrinsecamente mediada, que faz intermédio entre nossas identidades coletiva e individual, entre os processos de imagem mental e cultural, entre nosso passado e nosso futuro.

Objetos de memória mediada estão sempre em movimento, como agentes no processo de reconstrução da memória, sempre motivados pelo desejo. Assim, o ato fotográfico é sempre um ato de memória, mas pode ser também um ato de esquecimento. "Nós aparentemente podemos resistir às fotografias da maneira como resistimos às memórias, não somente por literalmente destruí-las, mas também simplesmente as barrando de entrar no olho da mente" (DIJCK, 2007, p. 103, tradução dos autores) $)^{8}$.

Assim, ao perguntar no dia seguinte se os participantes se lembravam de um objeto fotografado ou não, a pesquisa de Henkel deixa de lado uma série de outras variáveis presentes no processo do ato fotográfico. É por isso que, na construção da memória, o que se fotografa importa mais do que o ato fotográfico em si.

Em seu artigo, Henkel (2013) não discute o advento do digital como mais ou menos eficiente no processo de rememoração, mas é algo que se encontra implícito inclusive na repercussão da pesquisa, com reportagens que muitas vezes destacam ferramentas de compartilhamento como inimigos da memória ( $\mathrm{O}$ Instagram pode estar arruinando suas memórias) (LARSON, 2013), com o estabelecimento da noção de que a proliferação de imagens é grande inimiga da memória. Para Dijck (2007), as transformações do mundo digital desafiam a mente humana a desenvolver novas formas de seleção, entendimento e lembrança das informações.

\section{Por que nós fotografamos?}

$8 \quad$ No original: We can apparently resist photographs the way we resist memories, not just by literally destroying them but also by simply barring them from entering the mind's eye. 
Fotografar objetos em uma visita a um museu pode ser visto não apenas como uma tentativa de se lembrar do ocorrido posteriormente, mas como uma forma de engrandecer a própria experiência. Ao produzirmos uma fotografia, nosso objetivo não é o mero registro documental, como estabelecido no experimento de Henkel (2013), mas a comunicação do que nos aconteceu naquele determinado momento, principalmente hoje com o compartilhamento digital em redes sociais. Na criação da memória autobiográfica através das fotografias, sempre ocorre esse encontro do self com o social, no qual nossas memórias pessoais se articulam com outras memórias pessoais, e são revisadas, reinterpretadas, revividas, recriadas. Quando não considera o fator comunitário em seu experimento, Henkel (2013) deixa de lado uma etapa importante da construção da memória.

É difícil isolar o ato fotográfico como uma prática mecânica ao tentar pensá-lo como uma prática para memória. Afinal, a expansão dos arquivos fotográficos está intimamente conectada ao processo de formação do self, junto com vídeos domésticos, diários, listas de músicas, perfis de redes sociais, correspondências etc. Ao longo do tempo, a identidade passa a ser construída pela observação, leitura, releitura e reinterpretação dos significados desses objetos. O impacto da fotografia na memória, portanto, não pode ser medido de um dia para o outro, afinal é um processo criativo de reconstrução do passado, assim como a imaginação o é para o presente.

As memórias são efetivamente reescritas a cada vez que são ativadas; no lugar de lembrar reavivar uma memória guardada há tempos, o cérebro está formando-a novamente em um novo contexto associativo. Toda memória, portanto, é uma nova memória porque é formada (ou reconsolidada) pelas mudanças que ocorreram em nosso cérebro desde a última vez em que ela nos ocorreu (DIJCK, 2007, p. 32, tradução dos autores) ${ }^{9}$.

9 No original: Memories effectively are rewritten each time they are 
Joe Miller é um artista americano de 25 anos, que, em 2014, sofreu um derrame que o deixou em coma por duas semanas. Ao acordar, foi constatado que Miller havia perdido $95 \%$ de suas memórias. Em busca do que perdeu, Miller descobriu que costumava ser um usuário frequente do aplicativo social Instagram. Em seu perfil, ele redescobriu antigos hábitos, seus amigos, suas obras de arte. "Agradeço à Deus pelo Instagram. [...] É insano como aquelas pequenas parcelas de memórias - vídeos, legendas, fotos - engatilhavam certas memórias", afirma Miller em reportagem (PEOPLE STAFF, 2005). "Olhando essas imagens e vídeos antigos, eu não conseguia lembrar da história toda, mas sabia o suficiente para me trazer um riso à face", diz. Sem a vivência das rememorações, das camadas da memória que se criam ao longo do tempo, as fotografias do Instagram de Miller são novas memórias, que se tornam antigas a partir do exercício de sua imaginação. "Nossa habilidade de criar histórias do passado não depende em nossa habilidade de relembrar fatos precisos; ao contrário, histórias podem criar memórias" (DIJCK, 2007, p. 163, tradução dos autores).

Parece contraditório tentar entender o entrelaçamento da fotografia com a memória a partir de uma fotografia sem intenção, pré-determinada, pois há tantas intenções possíveis por trás do ato fotográfico: podemos fotografar só por fotografar, para compartilhar, pensando em criar memórias futuras, para registrar informações, para colecionar imagens, para provar algo futuramente, para assegurar que nos lembremos em casos de perda de memória, para "congelar o tempo", para estudar algo mais a fundo posteriormente, além de inúmeras outras possibilidades.

Ao fazer um registro fotográfico, também não estamos a par de seus futuros usos: são inúmeros os exemplos desses novos propósitos ou re-apropriações. Fotografias de famílias do século activated; instead of recalling a memory that has been stores some time ago, the brain is forging it all over again in a new associative contect. Every memory, therefore, is a new memory because is is shaped (or reconsolidated) by the changes that have happened to our brain since the memory last occurred to us. 
19 são itens comuns nas coleções dos museus de história, por exemplo, passando da esfera íntima da memória para compor uma coleção sobre memória coletiva. As mesmas fotografias podem se tornar objetos para uso estético de artistas que trabalham com found photography, como Rosângela Rennó ou Luc Boltanski. Uma fotografia postada nas redes sociais também pode ser re-apropriada por artistas contemporâneos, como Joachim Schmid ou Richard Prince.

Um importante objetivo do ato fotográfico é a criação de memórias futuras. Ao criarmos memórias, estamos propensos ao "wishful thinking"(DIJCK, 2007), expressão em inglês sem tradução direta para o português que nos traz a ideia de um pensamento desejante, uma auto-sugestão, uma utopia, uma fantasia, ligada a um excesso de otimismo. Gillian Rose (2010) entrevista diversas mães sobre sua relação com a fotografia e a família e elas revelaram que um dos principais motivos por que fotografam e organizam álbuns é porque desejam que, no futuro, seus filhos vejam como eles eram no passado. Utilizando o conceito de Barthes, ela fala de um "isso-foi do futuro", revelando a teia de temporalidades que existe na sucessão do ato fotográfico, da observação do resultado, na organização em álbuns, e nas diversas visitas que fazemos às fotografias que tiramos.

\section{O que fotografamos importa?}

Casey N. Cep, da revista New Yorker, usa a câmera de seu iPhone como uma espécie de caderno de anotações. "Não é que minha memória melhorou, mas eu comecei a arquivar os eventos e ideias em meu celular como fotografias. [...] A fotografia digital, infinita e barata, transformou todos em arquivistas" (CEP, 2014, tradução dos autores $)^{10}$. A repórter costuma revisitar frequentemente

10 No original: It's not that my memory improved but, instead, that I started archiving these events and ideas with my phone, as photographs. [...] 
suas fotografias, observando, reformulando. Em seu artigo, Henkel (2013) pondera que talvez nossas fotografias só possam nos ajudar a lembrar se nós as acessarmos e interagirmos com elas, no lugar de apenas acumulá-las. Para que haja essa interação posterior, contudo, é importante que, assim como nos mostra Casey, essas fotografias nos façam algum sentido. Para Dijck (2007), o processo constante de reconstrução de nossas memórias é motivado pelo desejo, mesmo motivo que nos leva ao ato fotográfico.

"O ato fotográfico submete o fotógrafo a uma sequência de decisões que mobiliza todas as esferas da subjetividade" (FONTCUBERTA, 2012, p. 188). Em tese, não há nada de robotizado ou pré-determinado no ato de fotografar. O Operator se utiliza de sentimento, emoções, interpretação e posicionamento quando aperta o "gatilho" da câmera, mesmo que tudo isso passe despercebido. Mesmo que esteja empreendendo uma tarefa que expresse uma vontade de fotocopiar o real, no ideal da representação, a própria tarefa implicará no ato de escolher (FONTCUBERTA, 2012). O ato de fotografar um objeto pré-selecionado em um museu não pode implicar em uma memória exata e absoluta desse objeto, já que essa fotografia por si só já não é uma representação exata, está sim imbuída de todo processo de subjetivação do ato fotográfico. Não se trata nem de uma fotocópia do real nem da memória dessa fotocópia.

Em A Câmara Clara, Barthes (1984) traça os conceitos de studium e punctum para o Spectator - aquele que olha. O primeiro trata de um elemento na imagem que provoca o interesse humano do ponto de vista cultural. Já o segundo denota uma subjetividade profunda, é aquilo que move, que punge, que fere o Spectator em determinada imagem. Há imagens onde nada promove esse tipo de reação: são puro studium. "Reconhecer o studium é fatalmente encontrar as intenções do fotógrafo, entrar em harmonia com elas, aprová-las, desaprová-las, discutí-las em mim mesmo, pois a cultura (com quem tem a ver o studium) é um contrato feito entre

Digital photography, endless and inexpensive, has made us all into archivists. 
os criadores e os consumidores" (BARTHES, 1984, p. 48).

O punctum é um detalhe que atrai o Spectator em determinada imagem, sua presença transforma a leitura, cria uma nova imagem, uma imagem superior. "Pela marca de alguma coisa, a foto não é mais qualquer. Esse alguma coisa deu um estalo, provocou em mim um pequeno abalo [...]" (BARTHES, 1984, p. 77).

Barthes não nos fala muito sobre o Operator - o fotógrafo: “dessa emoção (ou dessa essência) eu não podia falar, na medida em que nunca a conheci; não podia unir-me à coorte daqueles (os mais numerosos) que tratam da Foto-segundo-o-fotógrafo" (BARTHES, 1984, p. 21). Ele não contempla em sua obra, portanto, a situação de que falamos no presente artigo: a do Operator da fotografia vernacular, aquele que é ao mesmo tempo Operator e Spectator de suas memórias fotográficas.

Podemos, então, falar de um punctum que nos move a fotografar determinados objetos e não fotografar outros e usar a ideia deste elemento que agita e que marca para falar das fotografias de que nos lembramos. Da ausência deste punctum, surgem as fotografias de que nos esquecemos, porque não são gatilhos para emoções ou desejos. O efeito de prejuízo do ato fotográfico pode então estar aí, na ausência de algo que mova o Operator/Spectator a lembrar-se de algo que tenha fotografado.

\section{Considerações finais}

Se, por um lado, compreendemos a ansiedade do contemporâneo causada pela sensação de enxurrada de fotografias produzida pelos dispositivos onipresentes em nosso cotidiano, por outro, devemos ser cautelosos diante das conclusões distópicas que essa ansiedade pode causar. $\mathrm{O}$ debate sobre a eficácia ou não do uso da tecnologia para o auxílio da memória é recorrente na história da filosofia ocidental. É bem conhecida a passagem em que Platão, em um diálogo entre Sócrates e Fedro, condena a escrita, por ser 
prejudicial à memória.

Ela (a escrita) tornará os homens mais esquecidos, pois que, sabendo escrever, deixarão de exercitar a memória, confiando apenas nas escrituras e só se lembrarão de um assunto por força de motivos exteriores, por meio de sinais, e não dos assuntos em si mesmos (PLATÃO, 2000, p. 121).

É justamente o caráter de exterioridade da escrita que é criticado por Platão. Como uma espécie de "muleta", a escrita causaria uma atrofia na memória, que deixaria de ser exercitada ao se cristalizar em um objeto concreto e independente. No entanto, não fosse essa mesma técnica, nem mesmo teríamos tido acesso aos argumentos socráticos que chegaram a nós milhares de anos depois, através dos diálogos escritos por Platão ${ }^{11}$. Está claro que o maior problema é o que compreendemos por memória, seja no caso do argumento platônico, seja no estudo de Linda Henkel.

Bergson (1999, p. 85-99) faz uma distinção entre dois tipos de memória: a memória hábito, na maioria das vezes criada de forma consciente, ligada às ações cotidianas; e a memória por excelência, formada por imagens-lembranças, em que todo o nosso passado se encontra virtualmente. Podemos dizer que os resultados da pesquisa de Henkel dizem respeito apenas a esse primeiro tipo de memória, a uma racionalização dos mecanismos mneumônicos com um objetivo claro e mensurável.

Além disso, ela mesma admite que diversos elementos de uma situação real foram desprezados, como o afeto envolvido na escolha do objeto fotografado e o reencontro com essas imagens posteriormente. Quando revemos uma fotografia feita por nós (ou não), não lembramos apenas do objeto retratado, mas também de

11 Não vem ao caso aqui aprofundarmos a discussão platônica,que, sabemos, é bastante mais complexa e diz respeito a uma defesa da dialética como forma de retórica filosófica. Ver, por exemplo, RODRIGUES (2015). 
uma série de sentimentos, sensações e fatos que podem ser evocados por elementos presentes naquela imagem e que se relacionam com o presente de quem rememora. Ou seja, mesmo que o objetivo do ato fotográfico seja formar uma memória hábito, muitas vezes essas duas memórias se encontram e se confundem. Bergson exemplifica isso quando admite que, ao rememorar uma lição decorada, não temos acesso apenas ao conteúdo daquela lição, mas também somos confrontados com imagens-lembranças dos momentos sucessivos em que fizemos cada leitura (BERGSON, 1999, p. 86).

$\mathrm{O}$ artigo da pesquisadora americana não faz afirmações categóricas sobre o efeito do ato de fotografar na construção da memória, mas parte de uma situação específica e artificialmente realizada para chegar a conclusões parciais e inócuas que rapidamente foram lidas e divulgadas como generalizáveis. No entanto, é evidente que a capacidade ou não de recordação de características do objeto fotografado ou de seu título após um curto espaço de tempo não indica nada a respeito da memória como um processo vivo, virtual e em constante mutação.

\section{Referências}

ASSOCIATION FOR PSYCHOLOGICAL SCIENCE. No pictures, please: Taking photos may impede memory of museum tour, Psychological Science, 9 dez. 2013. Disponível em: <http:// www.psychologicalscience.org/index.php/news/releases/nopictures-please-taking-photos-may-impede-memory-of-museumtour.html>. Acesso em: 10 ago. 2015.

BARTHES, Roland. A câmara clara. Rio de Janeiro: Nova Fronteira, 1984.

BATCHEN, Geoffrey. Forget me not: photography and remembrance. New York: Princeton Architectural Press, 2004. 
BERGSON, Henri. Matéria e memória: ensaio sobre a relação do corpo com o espírito. São Paulo: Martins Fontes, 1999.

CEP, Casey N. A thousand words: writing from photographs. Revista New Yorker, 26 fev. 2014. Disponível em: <http://www. newyorker.com/books/page-turner/a-thousand-words-writingfrom-photographs $>$. Acesso em: 5 jul. 2015.

CHALABI, Mona. Does taking photographs ruin your memory. The Guardian, 31 nov. 2013. Disponível em: <http://www. theguardian.com/news/reality-check/2013/dec/10/does-takingphotographs-ruin-your-memory>. Acesso em: 16 jul. 2015.

DIJCK, José Van. Mediated memories in the digital age. Stanford: Stanford University Press, 2007.

FONTCUBERTA, Joan. A câmera de pandora: a fotografia depois da fotografia. São Paulo: Gustavo Gili, 2012.

HENKEL, Linda. Point-and-shoot memories: the influence of taking photos on memory for a museum tour. Psicological Science (Revista online), 5 dez. 2013. Disponível em: $<$ http://pss.sagepub. com/content/early/2013/12/04/0956797613504438, >. Acesso em: 5 jul. 2015.

. How our photo obsession is threatening our memories. Portal Quartz,25 dez.2014.Disponívelem: <http://qz.com/317428/ how-our-photo-obsession-is-threatening-our-memories/>. Acesso em: 6 jul. 2015.

KRACAUER, Siegfried. O ornamento da massa. São Paulo: Cosac Naify, 2009. 
LANDSBERG, Alison. Prosthetic memory: the transformation of american remembrance in the age of mass culture. New York: Columbia University Press, 2004.

LARSON, Selena. Instagram may be ruining our memories. Business Insider. 24 dez. 2013. Disponível em: http://www.businessinsider. com/instagram-may-be-ruining-our-memories-2013-12>. Acesso em: 6 jul. 2015.

Memento. In: DICIONÁRIO Oxford escolar : para estudantes brasileiros de inglês : português-inglês, inglês-potuguês. Oxford University Press, 2002. p. 500.

PEOPLE STAFF. Artist who lost all memories puts his life back togheter with the help of Art and Instagram, People, 26 abr. 2005. Disponível em: <http://www.people.com/article/stroke-victimremembers-life-with-instagram>. Acesso em: 6 jul. 2015.

PLATÃO. Fedro. Lisboa: Guimarães Editores, 2000.

RODRIGUES, Reginaldo Ferreira. Escrita e memória no Fedro de Platão. Griot - Revista de Filosofia, v. 11, n. 1, p. 100-115, jun. 2015.

ROSE, Gillian. Doing family photography: the domestic, the public, and the policits of sentiment. Farnham-Burlington: Ashgate Publishing Company, 2010.

STIER, Nicole. Shutterfly Research Reveals Americans Are Taking More Photos but Failing to Share More, 13 nov. 2014. Disponível em: $<$ http://ir.shutterfly.com/releasedetail.cfm?ReleaseID=882839>. Acesso em: 19 jul. 2015. 